Article

\title{
Decision and Coordination in a Low-Carbon E-Supply Chain Considering the Manufacturer's Carbon Emission Reduction Behavior
}

\author{
Qiang Han and Yuyan Wang * \\ School of Management Science and Engineering, Shandong University of Finance and Economics, Jinan 250014, \\ China; qiang.han@sdufe.edu.cn \\ * Correspondence: 20088164@sdufe.edu.cn or wangyuyan1224@126.com; Tel.: +86-158-066-47268
}

Received: 30 March 2018; Accepted: 19 May 2018; Published: 22 May 2018

check for updates

\begin{abstract}
At present, online shopping is becoming increasingly popular. In particular, low-carbon products are becoming more favored as consumers' low-carbon awareness increases. Manufacturers sell their low-carbon products through e-commerce platforms. Thus, the manufacturer and the e-commerce platform form a low-carbon e-supply chain system. The manufacturer makes products with carbon emission reduction efforts, while the e-commerce platform provides a sales service. In this paper, we described models for a decentralized decision mode and a centralized decision mode in the low-carbon e-supply chain, and compare the decision results. Our findings show that the centralized decision mode has a better performance than the decentralized one, the ability of the e-supply chain to respond to consumers' preference for a low-carbon product has a direct effect on its operation, and the manufacturer's carbon emission reduction behavior will be a potential source for enterprises to gain more revenue. Further, we designed a coordination contract for them that can be accepted by both sides in the decentralized decision mode. We find that if the e-commerce platform can share the carbon emission reduction costs of the manufacturer, the performance of the e-supply chain will be greatly improved. A practical case study and numerical examples validate our analysis.
\end{abstract}

Keywords: low-carbon e-supply chain; coordination mechanism; commission fee; carbon emission reduction cost

\section{Introduction}

With the rapid development of the Internet, online shopping has become accepted and preferred by more and more consumers because of the available products' novelty, cheapness, variety, fashion, and convenience. Its volume of business has greatly increased in recent years. In the United States (US), Black Friday online sales in 2017 reached a record $\$ 5.03$ billion, which was up 16.9\% from last year (Adobe Data Shows Cyber Monday Is Largest Online Sales Day in History with \$6.59 Billion. Available online: http://news.adobe.com/press-release/experience-cloud/adobedata-shows-cyber-monday-largest-online-sales-day-history-659 (accessed on 27 November 2017)), and Adobe Digital Insights research shows that online holiday sales in 2017 were $\$ 107.4$ billion, which was up 13.8\% from 2016 (5 Online Shopping Predictions For The 2017 Holiday Season. Available online: http:/ /www.cmo.com/adobe-digital-insights/articles/2017/10/27/us-adi-2017holiday-predictions.html\#gs.CHKc4aY (accessed on 2 November 2017)). What's more, these are not isolated figures. In China, total sales during the Tmall Double 11 Shopping Festival reached $¥ 168.2$ billion (for accuracy, we use the same currency unit as in the data source throughout this paper) in 2017 (China Double 11 Shopping Festival Sales Statistics 2017. Available online: https:/ / www.chinainternetwatch.com/22791/double-11-2017/ (accessed on 12 November 2017)). Due to the amazing volume of online shopping, manufacturers are ready to sell their goods on the 
e-commerce platform. The e-commerce platform and its settled sellers form a supply chain partnership that is based on investing together and sharing risk and revenue with each other. They work out internal decisions for the supply chain together to make the supply chain grow. In this way, the e-supply chain comes into being.

As one kind of business operation mode, the ultimate goal of the e-supply chain is to make profits for the supply chain and its member enterprises. Thus, it is particularly important for the manufacturers to understand what products are favored by consumers and thus should be produced, and for the e-commerce platform to decide how to sell the products to consumers through providing quality service. As can be seen everywhere, climate change and carbon emission are always hot topics. Carbon dioxide emissions in 2002 reached 40 billion tons, and are expected to reach 58 billion tons in 2030 [1]. In fact, most consumers have realized that excessive carbon emissions during production and consumption are one of the vital factors causing climate problems. The rise of environmental awareness directs consumers toward low-carbon consumption. In the United Kingdom (UK), carbon trust research shows that consumers prefer low-carbon products, even at a high price [2]. Vanclay, Shortiss, and Aulsebrook et al. concluded that low-carbon products sell better than high-carbon products, based on sales data in Australia [3]. In the US, $67 \%$ of consumers consider environmental benefit an important factor when shopping, and $51 \%$ are prepared to buy low-carbon products at a high price [4]. All of these cases show that environmental factors can affect the demand for products to a certain extent. Consumers with strong environmental awareness have certain low-carbon preferences, and tend to buy low-carbon products. This means that enterprises that adopt an environment-friendly strategy will help their products get favored by consumers, free them from the discrimination related to carbon emission, and increase their market share in competition with other products. After investigating world-famous large companies and some start-up companies, Plambeck found that consumers are ready to buy low-carbon products after understanding that low-carbon products will add to their private utility, and that consumers with a low-carbon preference prefer to trade with enterprises that not only make low-carbon products, but also publish their carbon emission reduction information objectively [5]. To simplify, we abbreviate carbon emission reduction as CER hereafter.

It is clear that consumers prefer low-carbon products. Thus, a low-carbon e-supply chain mode that sells low-carbon products within the e-supply chain, is also of great concern to enterprises and scholars. This field has been fruitful, published studies have involved the measurement of CER, optimization of marketing channels, evaluation of low-carbon system features, etc. However, they haven't taken the influence of the e-commerce platform into consideration. In an e-supply chain, as the sponsor of CER action, manufacturers still have to sell their products through the e-commerce platform, and how to share the revenue is also a common concern for them. So, the CER action of manufacturers will influence that of the e-commerce platform or supply chain, and vice versa. This dual relationship between manufacturers and the e-commerce platform caused by CER will inevitably have a great effect on the operation of the e-supply chain. However, this topic has yet to been touched upon in the existing research.

Based on the above analysis, this paper focuses on a low-carbon e-supply chain, in which the manufacturer sells low-carbon products through the e-commerce platform with which it cooperates. To describe the relation mentioned above, we take the CER efforts and response capability of the manufacturer to consumers' low-carbon preferences into consideration, present a low-carbon e-supply chain pricing strategy and service strategy, as well as the manufacturer's emission reduction strategy, further reveal the effect of the manufacturer's emission reduction strategy on the e-supply chain's decision, and further design an exclusive contract in order to achieve system coordination. Our contributions are:

(1) Since the e-commerce platform service level is an important factor influencing e-supply chain sales, this paper brings the e-commerce platform into the e-supply chain system to study the effect of the e-commerce platform service on the sales of low-carbon products. 
(2) This paper studies the effect of the manufacture's CER action on e-supply chain decisions, and works out the optimal strategy for both the manufacturer and the e-commerce platform to guide how the members in the e-supply chain should make decisions.

(3) This paper designs a coordination contract between the manufacturer and the e-commerce platform to balance the manufacturer's cost when developing low-carbon products. It can not only inspire the manufacturer's initiative for making low-carbon products, it can also direct the low-carbon e-supply chain on the road of sustainable and benign development.

The rest of this paper is organized as follows. In Section 2, we provide a review of the related literature. In Section 3, we give the background and assumptions for the model. In Section 4, we model the centralized decision mode and the decentralized decision mode; then, their optimal decisions are compared in Section 5. In Section 6, the coordination mechanism is designed. In Section 7, we do an example analysis. In Section 8, we offer concluding comments.

\section{Related Literature}

This study is closely related to three growing streams of literature: a low-carbon supply chain, an e-supply chain, and supply chain coordination.

\subsection{Low-Carbon Supply Chain}

For years, many companies have adopted the supply chain management mode. Due to its energy consumption etc., supply chain operation will inevitably affect the environment. To make it more sustainable, some researchers have combined the manufacturing process with the remanufacturing process through reverse logistics and green logistics [6,7]. Due to concerns about climate change and global warming, the world is reducing carbon emissions [8].

In fact, carbon emission should also be an important factor since its cost can change the optimal configuration of the supply chain [9]. Some researchers have addressed this problem by separating the function of the supply chain. Zheng, Liao, and Yang (2016) analyzed the effects of transportation mode on the optimum decisions and profits of low-carbon retailers [10]. Freis, Vohlidka, and Günthner (2016) developed reference building models for different types of logistics centers to help build a low-carbon warehouse. Both members in the supply chain and the whole supply chain itself can do something for reducing carbon emissions [11]. Good cooperation between enterprises in the supply chain is required; $\mathrm{Du}, \mathrm{Hu}$, and Wang (2017) considered the low-carbon efforts of the manufacturer and retailer in their rebuild of the business ecosystem, and designed a carbon-related price-discount sharing-like scheme to achieve channel coordination [12]. At the end of the supply chain, consumers also play an important role. Du, Zhu, and Jiao et al. (2015) analyzed the impact of consumers' preferences for low carbon in the emission-concerned supply chain, and found that the decision-maker of the supply chain would choose different emission reduction strategies for different cases [13]. Brandenburg (2015) optimized a supply chain configuration for a new consumer product through trade-offs between carbon emissions and financial value [14]. In practice, the low-carbon feature is used in the supply chain design of the construction industry [15], the electronic sector [16], the garment industry [17], etc.

Most of the current research about low-carbon supply chains has been focused on the traditional environment. However, the e-commerce supply chain has a very different operation mode than the traditional supply chain. The manufacturer directly sells products to the consumer through the e-commerce platform, and can determine the product price. Besides the service of the traditional retailer, the e-commerce platform also provides other services, such as advertising, logistics, an after-sale guarantee, etc. So, the existing methodology is not quite applicable. The low-carbon supply chain under the e-commerce environment should be developed further than the traditional model. Each member in the supply chain is not independent; they influence each other. In our opinion, it is the manufacturer that undertakes the production of low-carbon products, so its CER behavior should have an effect on the supply chain. What's different from the existing literature in this paper is that we 
will take its behavior into account in our analysis of how the supply chain should be designed in order to encourage the manufacturer's CER behavior and improve the performance of the supply chain.

\subsection{E-Supply Chain}

As one form of the supply chain, the e-supply chain was thought of as one commercial mode by Poirier and Bauer (2002) that would promote enterprise communication, develop new products and services that meet customer demand, improve process efficiency, keep a low inventory, and completely change the future [18]. So, the e-supply chain is important for a building sustainable supply chain system. After the e-commerce platform appeared as the third service provider, He, Xiong, and Lin (2016) evaluated the effect of the governmental e-commerce tax on carbon emissions [19]; Guo, Wang, and Fan et al. (2017) proposed a logistics network model that could be applied to the low-carbon environment, and provided a reference for the design of a forward and reverse logistics network of fresh food e-commerce enterprises [20]. Within e-supply chain practice, Valverde and Saadé (2015) took the North American electronic manufacturing industry as an example to stress the strength of the e-supply chain in improving efficiency and revenue [21]; Cagliano, Marco, and Rafele (2017) studied mobile services for supply chain management in the electronic grocery sector [22]; Kiselicki, Josimovski, and Joncheski (2014) summarized the obvious weak spots in the traditional supply chain that could be solved by the e-supply chain, and helped minor enterprises design functions such as e-commerce, e-procurement, and e-collaboration in the e-supply chain [23]. Piera, Roberto, and Giuseppe et al. (2014) analyzed the advantages and difficulties of implementing an e-supply chain, and defined its basic structure [24].

Recently, research has discussed the effect of e-commerce on the e-supply chain. As can be seen, most of the features focus on e-supply chain operation from a macroscopic view, in which the e-commerce platform is only considered as the external environment for supply chain operation, and hasn't been combined into the frame as an important member of the supply chain. Even less research has focused on the effect of the e-supply chain on carbon emissions. We will describe the interaction relation between members in the e-supply chain from a microscopic point of view.

\subsection{Supply Chain Coordination}

An introduction of the effective coordination mechanism into the supply chain will increase its revenue and reduce unnecessary cost [25], because supply chain members often make decisions that maximize their own revenue [26]. The coordination aims to provide accurate information and incentive for supply members by applying certain contracts. In general, the basic supply chain contract includes a sharing revenue contract [27-31], a buy-back contract [32-34], a quantity discount contract [35-37], a wholesale pricing contract [38-40], and a quantity-flexibility contract [41,42]. Alongside these, some special contracts have also been designed to coordinate the supply chain. Jaber, Glock, and Saadany (2013) designed a coordination mechanism with a two-level supply chain model for the European Union Emissions Trading System, which can minimize inventory-related and greenhouse gas (GHG) emission costs [43]. Bi (2017) considered how to develop e-supply chain coordination capability in small-to-medium enterprises, and found that e-supply chain coordination is driven by IT infrastructure, business partnerships, and customer power [44].

So, basic supply chain contracts are the basis for some problems, and they cannot be applied to all cases. Many new contracts could be derived from the basic ones. Under the e-commerce environment, the e-commerce platform isn't related to the product price. There is no wholesale price between the e-commerce platform and the manufacturer. The key variable that allocates profit is the commission fee, which is also the main financing source for the e-commerce platform to provide the sale service. In this paper, we will select the commission fee as the coordination tool, and design a special contract for members in the e-supply chain. 


\section{Background and Assumptions of the Model}

We consider a low-carbon e-supply chain consisting of one manufacturer and one e-commerce platform, in which the manufacturer not only makes low-carbon products with CER behavior, but also publishes sales information through the e-commerce platform to sell them. Accordingly, the manufacturer has to pay the commission fee to the platform. The model structure is shown in Figure 1.

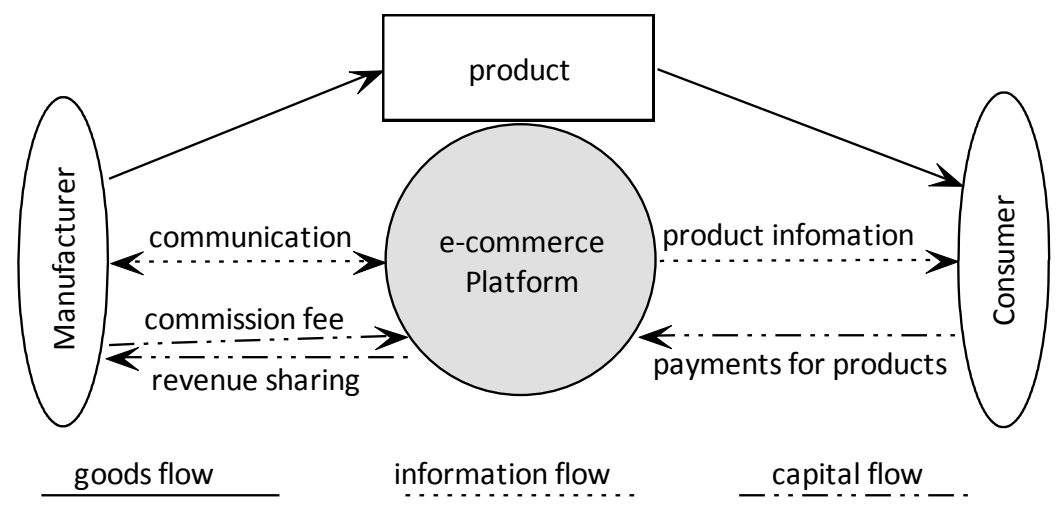

Figure 1. E-supply chain structure.

In practice, an e-supply chain runs in the following way. First, the e-commerce platform releases qualification requirements and a charging standard to the manufacturers that plan to register on it. Second, manufacturers offer the qualification certificates to be checked, and enter them into the platform if they are confirmed. Then, the e-commerce platform renders a service for the manufacturer. When entering the e-commerce platform, the manufacturer must pay two kinds of fees to the platform. One is a fixed fee, such as the annual fee and deposit, which are only used to guarantee the base service from the e-commerce platform, e.g., the manufacturer is qualified to publish product information. The other is the variable fee, which is charged by the e-commerce platform according to the manufacturer's sales, and the e-commerce platform will offer different services based on how much has been charged, such as for the product ad, a quick goods return or exchange, sales operation, storage, logistics, payment, customer service, after-sale service, credit maintenance, etc. For example, Tmall, a B2C (Business to Customer) e-commerce platform of the Alibaba Group, has taken in thousands of brands and provided a one-stop shopping service for sellers and consumers. Its charge consists of three parts: the deposit, a technical service annual fee, and a technical service fee. The related regulations for sellers to enter Tmall are as follows.

(1) Merchants that run at Tmall must pay a deposit, which is to guarantee that merchants will operate complying with Tmall Service Protocol and Tmall regulations. Merchants will be charged a penalty if they break them. See Table 1.

(2) Merchants that run at Tmall must pay the technical service annual fee, which has two classes, $¥ 30,000$ and $¥ 60,000$, based on goods classification. See Table 2 for some examples.

(3) Merchants that run at Tmall must pay the technical service fee proportional to their sales. See Table 2 for some examples of technical service fee rates.

It's obvious that the first two parts belong to fixed fee, and the third one is the variable fee.

Table 1. Deposit in Tmall (¥10,000).

\begin{tabular}{ccc}
\hline Store Type & $\begin{array}{c}\text { Stores Holding Notice of Trademark } \\
\text { Registration Acceptance }\end{array}$ & $\begin{array}{c}\text { Stores Holding Registered } \\
\text { Trademark }\end{array}$ \\
\hline $\begin{array}{c}\text { flagship or speciality store } \\
\text { monopolized store }\end{array}$ & 10 & 5 \\
\hline
\end{tabular}


Table 2. Technical service annual fee and technical service fee rate in Tmall.

\begin{tabular}{cccccc}
\hline Fee Type & $\begin{array}{c}\text { Women's } \\
\text { Dress }\end{array}$ & $\begin{array}{c}\text { Smart } \\
\text { Wristwatch }\end{array}$ & $\begin{array}{c}\text { Color Cosmetics/ } \\
\text { Perfume/Beauty Tool }\end{array}$ & $\begin{array}{c}\text { Instrument } \\
\text { Service }\end{array}$ & Smart Phone \\
\hline $\begin{array}{c}\text { technical service } \\
\text { annual fee } \\
(¥ 10,000)\end{array}$ & 6 & 6 & 3 & 3 & 3 \\
$\begin{array}{c}\text { technical service } \\
\text { fee rate (\%) }\end{array}$ & 5 & 2 & 4 & 0.5 & 2 \\
\hline
\end{tabular}

With the understanding of how the e-commerce platform and the manufacturer operate at present, we also put forward the following assumptions for the model.

(1) In the e-supply chain, the e-commerce platform is the leader with the decision priority.

(2) The e-commerce platform collects commissions proportional to the product sales.

(3) The price of the low-carbon product is constant. The reason lies in that much of the investment in the fixed asset is needed for the manufacturer to design and make low-carbon products, and under the trend of low-carbon consumption, consumers will be accepting the low-carbon products for a certain time [5].

For simplicity, we introduce some symbols that will be used frequently in this paper.

$c$-cost of the manufacturer.

$q$-demand of the low-carbon product.

$p$-unit price of the low-carbon product.

$f$-fixed technical fee that the manufacturer gives to the e-commerce platform in one sales period.

$\rho$-commission rate, the proportion of sales collected by the e-commerce platform. General commission collected by the e-commerce platform is $\rho p q$.

$s-$ service level of the e-commerce platform. The better service level it provides, the more service cost it takes. We assume that service cost function of the e-commerce platform is $C_{e}(s)=k s^{2} / 2$ as Wu [45] did, in which $k(k>0)$ is the service cost parameter.

$h-$ CER level of the manufacturer. The better the carbon emission level, the higher the cost. According to the findings of Nair and Narasimhan [46], the relation of CER cost and CER level is subject to $C_{m}(h)=t h^{2} / 2$, in which $t(t>0)$ is the CER cost parameter.

In an e-supply chain, the demand for the low-carbon product is usually related to price, the CER level of the manufacturer, and the service level of the e-commerce platform. According to the assumption given by Yao and Liu [47]:

$$
q=\alpha-\beta p+\gamma s+\lambda h, \alpha, \beta, \gamma>0
$$

where $\alpha$ is a large enough number to denote the potential maximum demand, $\beta$ is the elasticity coefficient of the price, $\gamma$ represents the elasticity coefficient of the service level, and $\lambda$ indicates the elasticity coefficient of the CER.

Based on the above assumptions, we have the following equations.

The profit function of the manufacturer is:

$$
\pi_{m}=(1-\rho) p q-c q-t h^{2} / 2-f
$$

The profit function of the e-commerce platform is:

$$
\pi_{e}=\rho p q-k s^{2} / 2+f
$$

The general $r$ Profit function of the whole e-supply chain is:

$$
\pi=\pi_{m}+\pi_{e}=p q-c q-k s^{2} / 2-t h^{2} / 2
$$


According to the finding of Yu, Wang, and Zhong, et al., $t \gamma^{2}+k \lambda^{2}<2 k t \beta$ is assumed to ensure that the manufacturer's emission reduction input is positive [48].

\section{Model Formulations of Low-Carbon E-supply Chain Decisions Considering the Manufacturer's CER Behavior}

In this section, we present model formulations for the decentralized decision mode and the centralized decision mode, which illustrate how the low-carbon e-supply chain runs based on the different strategy that is adopted by the manufacturer and the e-commerce platform.

\subsection{Model I: Decentralized Decision Mode}

When running in this mode, the manufacturer and the e-commerce platform are independent economies. Both of them make decisions to maximize their respective revenue. The e-commerce platform is the leader, while the manufacturer is the follower. So, when making decisions, the e-commerce platform offers its service level first; then, the manufacturer determines its product price $p$ and CER level $h$. They form a Stackelberg game [49]. Their profit game function is described as follows:

$$
\begin{gathered}
\max _{s} \pi_{e}=\rho p q-k s^{2} / 2+f \\
\text { s.t. } \max _{p, h} \pi_{m}=(1-\rho) p q-c q-t h^{2} / 2-f
\end{gathered}
$$

In the following, we obtain the optimal decision in this mode with backward induction. Backward induction is a basic approach to reach subgame perfect Nash equilibrium in dynamic games of perfect information. It proceeds by first considering the optimal choice of the last subgame in a dynamic game. Using this information, the game player then determines in an inverted sequence the optimal choice in each subgame; then, finally the dynamic games subgame perfect Nash equilibrium is reached [49].

In Equation (1), the Hessian matrix of $\pi_{m}$ with respect to $p$ and $h$ is:

$$
H=\left[\begin{array}{cc}
\frac{\partial^{2} \pi_{m}}{\partial p^{2}} & \frac{\partial^{2} \pi_{m}}{\partial \partial h} \\
\frac{\partial^{2} \pi_{m}}{\partial h \partial p} & \frac{\partial^{2} \pi_{m}}{\partial h^{2}}
\end{array}\right]=\left[\begin{array}{cc}
-2 \beta(1-\rho) & \lambda(1-\rho) \\
\lambda(1-\rho) & -t
\end{array}\right]
$$

Since $t \gamma^{2}+k \lambda^{2}<2 k t \beta$, then $2 t \beta>\lambda^{2}$, thus $2 t \beta>\lambda^{2}(1-\rho)$, and $H$ is the negative definite matrix. By simultaneously solving $\frac{d \pi_{m}}{d p}=0$ and $\frac{d \pi_{m}}{d h}=0$, the response function of $p$ and $h$ is:

$$
\begin{gathered}
p_{1}^{*}=\frac{t[(1-\rho)(\alpha+s \gamma)+c \beta]-c \lambda^{2}(1-\rho)}{2 t \beta(1-\rho)-\lambda^{2}(1-\rho)^{2}} \\
h_{1}^{*}=\frac{\lambda[(1-\rho)(\alpha+s \gamma)-c \beta]}{2 t \beta-\lambda^{2}(1-\rho)}
\end{gathered}
$$

Substitute them in Equation (2) and let $\frac{d \pi_{e}}{d s}=0$; then, we can get the optimal service level of the e-commerce platform. This can be concluded in Conclusion 1.

Conclusion 1. In the decentralized decision mode,

The optimal product price is:

$$
p_{1}^{*}=\frac{1}{1-\rho} \cdot \frac{\left.k A\left[\left(t \alpha-c \lambda^{2}\right)(1-\rho)+c t \beta\right)\right]-c t^{2} \beta \gamma^{2} \rho}{k A^{2}-2 t^{2} \beta \gamma^{2} \rho}
$$

The optimal CER level of the manufacturer is:

$$
h_{1}^{*}=\lambda \frac{k A B+c t \beta \gamma^{2} \rho}{k A^{2}-2 t^{2} \beta \gamma^{2} \rho}
$$


The optimal service level of the e-commerce platform is:

$$
s_{1}^{*}=\frac{t \beta \gamma \rho\left(2 t \alpha-c \lambda^{2}\right)}{k A^{2}-2 t^{2} \beta \gamma^{2} \rho}
$$

Accordingly,

The optimal profit of the manufacturer is:

$$
\pi_{m}^{*}=\frac{t A\left(k A B+c t \beta \gamma^{2} \rho\right)^{2}}{2(1-\rho)\left(k A^{2}-2 t^{2} \beta \gamma^{2} \rho\right)^{2}}-f
$$

The optimal profit of the e-commerce platform is:

$$
\pi_{e}^{*}=\frac{t \beta \rho\left[2 k B(c A+t B)+c^{2} t \beta \gamma^{2} \rho\right]}{2(1-\rho)^{2}\left(k A^{2}-2 t^{2} \beta \gamma^{2} \rho\right)}+f
$$

And the optimal profit of the e-supply chain is:

$$
\pi_{1}=\frac{t}{2 D^{2}}\left[k t^{2} \beta^{2} \gamma^{2}\left(2 t \alpha-c \lambda^{2}\right)^{2} \rho^{2}-\lambda^{2} C^{2}+\frac{2 c \beta C D}{1-\rho}+\frac{2 \beta(1+\rho) C\left[c t^{2} \beta \gamma^{2} \rho+k A(t B-c A)\right]}{(1-\rho)^{2}}\right]
$$

In which, $A=2 t \beta+\lambda^{2}(\rho-1), B=c \beta+\alpha(\rho-1), C=k A B-c t \beta \gamma^{2} \rho, D=k A^{2}-2 t^{2} \beta \gamma^{2} \rho$.

\subsection{Model II: Centralized Decision Mode}

In the centralized decision mode, the manufacturer and the e-commerce platform cooperate when making decisions to maximize the total profit of the e-supply chain. Their decision model is formulated as follows.

$$
\max _{p, h, s} \pi_{2}=p q-c q-k s^{2} / 2-t h^{2} / 2
$$

The Hessian matrix of $\pi_{2}$ with respect to $p, h$ and $s$ is:

$$
\left[\begin{array}{lll}
\frac{\partial^{2} \pi_{2}}{\partial p^{2}} & \frac{\partial^{2} \pi_{2}}{\partial p h} & \frac{\partial^{2} \pi_{2}}{\partial p \partial s} \\
\frac{\partial^{2} \pi_{2}}{\partial h \partial p} & \frac{\partial^{2} \pi_{2}}{\partial h^{2}} & \frac{\partial^{2} \pi_{2}}{\partial h \partial s} \\
\frac{\partial^{2} \pi_{2}}{\partial s \partial p} & \frac{\partial^{2} \pi_{2}}{\partial s \partial h} & \frac{\partial^{2} \pi_{2}}{\partial s^{2}}
\end{array}\right]=\left[\begin{array}{ccc}
-2 \beta & \lambda & \gamma \\
\lambda & -t & 0 \\
\gamma & 0 & -k
\end{array}\right]
$$

Since $t \gamma^{2}+k \lambda^{2}<2 k t \beta$, the Hessian matrix of $\pi_{2}$ with respect to $p, h$, and $s$ is a negative definite. By $\frac{d \pi_{2}}{d p}=0, \frac{d \pi_{2}}{d h}=0$, and $\frac{d \pi_{2}}{d s}=0$, the optimal decision of the e-supply chain can be obtained as shown in Conclusion 2.

Conclusion 2. In the centralized decision mode,

The optimal product price is:

$$
p_{2}^{*}=\frac{k t(\alpha+c \beta)-c\left(t \gamma^{2}+k \lambda^{2}\right)}{2 k t \beta-t \gamma^{2}-k \lambda^{2}}
$$

The optimal CER level of the manufacturer is:

$$
h_{2}^{*}=\frac{(\alpha-c \beta) k \lambda}{2 k t \beta-t \gamma^{2}-k \lambda^{2}}
$$


The optimal service level of the e-commerce platform is:

$$
s_{2}^{*}=\frac{(\alpha-c \beta) t \gamma}{2 k t \beta-t \gamma^{2}-k \lambda^{2}}
$$

And the optimal profit of the e-supply chain is:

$$
\pi_{2}^{*}=\frac{k t(\alpha-c \beta)^{2}}{4 k t \beta-2 t \gamma^{2}-2 k \lambda^{2}}
$$

\section{Model Analysis}

We compare the optimal solutions of these two decision modes in Section 4, as shown in Propositions 1-4. In fact, they describe how the manufacturer's CER behavior influences the e-supply chain.

Proposition 1. $p_{1}^{*}$ and $p_{2}^{*}$ are direct proportional to $\lambda$, respectively.

See Appendix A for Proof of Proposition 1.

It can be known from Proposition 1 that the product price will always increase in either mode with the rise of the ability to respond to consumers' preferences for the low-carbon product. This reveals that it needs more investment to make the low-carbon product; the proper rise of the product price indicates the efforts that the supply chain has made, and at the same time, the consumer would rather buy the low-carbon product, even at a higher price.

Research conducted by the Carbon Trust has revealed that consumer carbon footprint awareness is promoting the development of low-carbon products, and consumers are happy to buy products at a high price if they know that the carbon emissions have been reduced across the supply chain (Low carbon products in demand despite challenging economic climate. Available online: https:/ / www.theguardian.com/environment/2011/jul/01/carbon-trust-research-footprintconsumer-demand (accessed on 1 January 2018)).

Proposition 2. CER level satisfies $h_{1}^{*} \leq h_{2}^{*}$. $h_{1}^{*}$ is reverse proportional to $\rho$, while $h_{2}^{*}$ is independent of $\rho . h_{1}^{*}$ and $h_{2}^{*}$ are direct proportional to $\lambda$, respectively.

See Appendix B for Proof of Proposition 2.

The potential meaning of Proposition 2 is that:

(1) In the centralized decision mode, the supply chain as a whole doesn't involve how to allocate the revenue; thus, the CER level won't change with the commission rate. This also means that the CER decision of the manufacturer won't be influenced by how the e-commerce platform makes decisions. However, the manufacturer will keep improving the CER level with the rise of the ability to respond to consumer preference for the low-carbon product.

(2) In the decentralized decision mode, if the e-commerce platform, as the leader, holds a higher proportion of the revenue, then the manufacturer will choose to keep reducing the CER level to cut down production costs and obtain more revenue. When the manufacturer's ability to respond to consumers' preference for the low-carbon product rises, the supply chain may try to increase the CER level to meet the demand of consumers.

Statistics from the Carbon Trust in 2011 showed that $45 \%$ of consumers would refuse to buy products from manufacturers who don't make low-carbon products. The rate has doubled over the past year, from $22 \%$. At the same time, brand loyalty is not optimistic, either. Only $56 \%$ of the shoppers would be more loyal to a manufacturer even if manufacturers were committing 
to CER (Low carbon products in demand despite challenging economic climate. Available online: https:/ / www.theguardian.com/environment/2011/jul/01/carbon-trust-research-footprintconsumer-demand (accessed on 1 January 2018)). So, the manufacturers have ongoing pressure to improve their CER level.

Proposition 3. The service level of an e-commerce platform satisfies $s_{1}^{*} \leq s_{2}^{*}$. $s_{1}^{*}$ and $s_{2}^{*}$ are directly proportional to $\lambda$, respectively.

See Appendix C for Proof of Proposition 3.

We can see from Proposition 3 that:

(1) In the centralized decision mode, the e-commerce platform collaborates with the manufacturer to run the supply chain in the optimal condition, so that the supply chain can offer a better service level. With the rise of the ability to respond to consumer preference for the low-carbon product, the product price will rise as shown in Proposition 1, and correspondingly, the supply chain has to improve their service level to attract enough consumers.

(2) In the decentralized decision mode, the e-commerce platform needs to spend the revenue it obtained from offering the sales service; thus, its basis for making decisions is how much revenue it tends to own, which is also related to its ability to respond to consumer preference for the low-carbon product. A higher response ability means much more investment, so the supply chain will increase the product price due to rising costs, while improving the service level will be the attractive point for the supply chain to keep customers.

On 25 April 2017, JD.com, a famous e-commerce platform in China, announced the establishment of JD Logistics, signifying that JD.com would start providing its logistics services to businesses across a wide range of industries. Its supply chain and logistics services have never been emphasized so much. In contrast to traditional slow and inefficient logistics, by building a smart supply chain with technological innovation, JD.com will help Chinese business reduce their logistics costs and improve their logistics efficiency and service standards (People's Daily supports JD.com: to improve service quality is right, and obligation as well (In Chinese). Available online: https:/ /baijiahao.baidu.com/s? $\mathrm{id}=1574047814845959 \& \mathrm{wfr}=$ spider\&for=pc (accessed on 10 January 2018)).

Proposition 4. The revenue of the e-supply chain satisfies $\pi_{1}^{*} \leq \pi_{2}^{*}$. $\pi_{1}^{*}$ is reversely proportional to $\rho$, while $\pi_{2}^{*}$ is independent of $\rho . \pi_{1}^{*}$ and $\pi_{2}^{*}$ are directly proportional to $\lambda$, respectively.

See Appendix D for Proof of Proposition 4.

Proposition 4 indicates that the revenue of the low-carbon e-supply chain, considering the manufacturer's CER behavior, is closely related to its decision mode.

(1) In the centralized decision mode, information sharing between nodes in the supply chain lets them maximize the revenue of the whole supply chain by determining the optimal decision variables. That's why they can achieve much higher revenue.

(2) In the decentralized decision mode, the larger $\rho$ is, the more revenue proportion the e-commerce platform can occupy. This results in a greater inequality between the manufacturer and the e-commerce platform, which not only makes the manufacturer obtain even less negative revenue, it also undermines the profitability of the whole supply chain. The rise of $\lambda$ indicates a better ability to meet consumers' low-carbon product preference, which then stimulates demand of the products. As a result, the supply chain inevitably gets more revenue in both modes.

For example, Gree Electric Appliances, which is well known for its low-carbon products, is a real winner through its positive cooperation with the e-commerce platform. Among all of the air conditioners that Gree has produced, the constant-frequency wall-mounted type with Energy 
Efficiency Class III accounts for 96.1\%, and floor-standing type, 98\%. In 2015, its gross profit margin of air conditioners was $36 \%$ and business income was $¥ 83.7$ billion; these figures were $38.54 \%$ and $¥ 88.1$ billion respectively in 2016; and 38.46\% and $\$ 54.6$ billion respectively in the first half of 2017 (How does Gree achieve best sales and profit? (In Chinese) Available online: http:/ / www.jiemian. com/article/1644335.html (accessed on 5 January 2018)).

\section{Coordination Mechanism}

As shown in Section 5, the centralized decision mode is better than the decentralized one. The former helps achieve the optimal revenue of the system, while the latter causes a loss of efficiency because of double marginalization. So, we introduce a certain coordination mechanism to the supply chain in the decentralized decision mode. For the traditional supply chain, many scholars have designed coordination mechanisms and realized Pareto improvement based on various contracts, i.e., revenue-sharing contracts [50] and quantity discount contracts [51]. In this paper, based on the theoretical knowledge of coordination, we propose a "Commission Fee Readjusting and Cost Sharing (hereafter called CFRCS)" contract to achieve coordination.

In the e-supply chain, revenues of the manufacturer and the e-commerce platform are closely related to the cost of the commission fee and the fixed fee. The e-commerce platform is the leader that determines the standard of the commission fee and fixed fee. Therefore, we select the commission fee as the coordination tool, and design the Commission Fee Readjusting and Cost Sharing (hereafter called CFRCS) coordination mechanism.

The CFTCS principle is that the platform should (1) readjust the commission fee based on the manufacturer's product price and cost; (2) increase the fixed technical fee according to service cost; and (3) share the manufacturer's cost for CER as a support to what it has done.

Assume that the e-commerce platform readjusts the commission fee rate to $\bar{\rho}$, fixed technical fee to $\bar{f}$, and also assume the proportion of the manufacturer's cost for CER that the e-commerce platform shares to be $\mu$; then, the manufacturer will still pay for $(1-\mu)$ of the whole cost, in which $0 \leq \mu \leq 1$. Thus, we get:

The profit function of the manufacturer is:

$$
\bar{\pi}_{m}=(1-\bar{\rho}) p q-c q-(1-\mu) \frac{t h^{2}}{2}-\bar{f}
$$

The profit function of the e-commerce platform is:

$$
\bar{\pi}_{e}=\bar{\rho} p q-\frac{k s^{2}}{2}-\mu \frac{t h^{2}}{2}+\bar{f}
$$

Conclusion 3. CFRCS can let the supply chain be coordinated if $(\bar{\rho}, \mu, \bar{f})$ satisfies:

$$
\left\{\begin{array}{c}
\bar{\rho}=\frac{(1-\theta)(p-c)}{p} \\
\mu=1-\theta \quad, 0<\theta<1 \\
\bar{f}=f+\theta \frac{k s^{2}}{2}
\end{array}\right.
$$

Proof. If $(\bar{\rho}, \mu, \bar{f})$ satisfies:

$$
\left\{\begin{array}{c}
\bar{\rho}=\frac{(1-\theta)(p-c)}{p} \\
\mu=1-\theta \quad, 0<\theta<1 \\
\bar{f}=f+\theta \frac{k s^{2}}{2}
\end{array}\right.
$$


Then, the manufacturer's profit is:

$$
\begin{aligned}
& \bar{\pi}_{m}=(1-\bar{\rho}) p q-c q-(1-\mu) \frac{t h^{2}}{2}-\bar{f} \\
& =\left[1-\frac{(1-\theta)(p-c)}{p}\right] p q-c q-\theta \frac{t h^{2}}{2}-\theta \frac{k s^{2}}{2}-f \\
& =\theta\left[(p-c) q-\frac{t h^{2}}{2}-\frac{k s^{2}}{2}\right]-f \\
& =\theta \pi-f
\end{aligned}
$$

The e-commerce platform's revenue is:

$$
\begin{aligned}
& \bar{\pi}_{e}=\bar{\rho} p q-\frac{k s^{2}}{2}-\mu \frac{t h^{2}}{2}+\bar{f} \\
& =(1-\theta)(p-c) q-\frac{k s^{2}}{2}-(1-\theta) \frac{t h^{2}}{2}+f+\theta \frac{k s^{2}}{2} \\
& =(1-\theta)\left[(p-c) q-\frac{k s^{2}}{2}-\frac{t h^{2}}{2}\right]+f \\
& =(1-\theta) \pi+f
\end{aligned}
$$

So, after the CFRCS mechanism is applied, both the profit function of the manufacturer and the e-commerce platform are affine functions of the supply chain profit; thus, the system can be coordinated. $\square$

To guarantee that both sides are willing to accept this coordination mechanism, a necessary condition is that they can obtain no less revenue than in the decentralized decision mode, that is:

$$
\left\{\begin{array}{l}
\bar{\pi}_{m}=(1-\bar{\rho}) p q-c q-(1-\mu) \frac{t h^{2}}{2}-\bar{f} \geq \pi_{m}^{*} \\
\bar{\pi}_{e}=\bar{\rho} p q-\frac{k s^{2}}{2}-\mu \frac{t h^{2}}{2}+\bar{f} \geq \pi_{e}^{*}
\end{array}\right.
$$

As a result, we have:

$$
\theta \in\left[\frac{2\left(f+\pi_{m}^{*}\right)\left(2 k t \beta-t \gamma^{2}-k \lambda^{2}\right)}{k t(\alpha-c \beta)^{2}}, \frac{k t(\alpha-c \beta)^{2}-2\left(\pi_{e}^{*}-f\right)\left(2 k t \beta-t \gamma^{2}-k \lambda^{2}\right)}{k t(\alpha-c \beta)^{2}}\right]
$$

Expression (4) is just the feasible condition of the coordination mechanism, in which the coefficient $\theta(0<\theta<1)$ indicates the manufacturer's bargaining power in this mechanism. The larger $\theta$ is, the more revenue the manufacturer can share, and the less for e-commerce platform.

Further, we have the following propositions.

Proposition 5. The lower bound of $\theta$ (the manufacturer's bargaining power in the CFRCS mechanism) is reversely proportional to $\lambda$ (elasticity coefficient of CER) and $\gamma$ (elasticity coefficient of service level), while its upper bound is directly proportional to them, respectively.

See Appendix E for the Proof of Proposition 5.

It derives from Proposition 5 that with the rise of $\lambda$ (the elasticity coefficient of CER) and $\gamma$ (the elasticity coefficient of the service level), the range of $\theta$ (the manufacturer's bargaining power in the CFRCS mechanism) will be expanded. If $\lambda$ and $\gamma$ become larger, then the product sales will rise, and the revenue that the manufacturer obtains by selling products will be much more. So, in the CFRCS mechanism, when $\lambda$ and $\gamma$ are getting larger, indicating their more powerful ability to respond to consumer preference for the low-carbon product and the higher service level of the e-commerce platform, the manufacturer will gain much more revenue with the rise of product sales, and as shown in Proposition 4, the supply chain also obtains much more revenue. Then, the e-commerce platform has an expanded space to share the manufacturer's cost for CER. Generally, both sides gain much more revenue. As the leader, the e-commerce platform has been allowed more freedom of action. That is why the CFRCS mechanism is feasible. 
Proposition 6. The lower bound of $\theta$ (the manufacturer's bargaining power in the CFRCS mechanism) is direct proportional to $\beta$ (elasticity coefficient of price), while its upper bound is reverse proportional to it.

See Appendix E for the Proof of Proposition 6.

It can be indicated by Proposition 6 that with the rise of the elasticity coefficient of price, the range of the manufacturer's bargaining power in the CFRCS mechanism will be shrunk. When $\beta$ grows higher, consumers will be more sensitive to the price; then, product sales decline, and the revenue that the manufacturer obtains by selling products will be less. So, in the CFRCS mechanism, if $\beta$ becomes larger, the lower revenue of the manufacturer that is gained from product sales means that the e-commerce platform has to share more of its cost for CER. This action can avoid the negative effect of reducing the revenue of the manufacturer, promote its continuous behavior to improve the CER level, and in the end help the supply chain achieve more revenue, as demonstrated in Proposition 4. This still indicates the feasibility of the CFRCS mechanism.

\section{Example Analysis}

In this section, we use both practical case and numerical examples to compare the decision modes and verify the effectiveness of our coordination mechanism.

\subsection{Practical Case}

Gree Electric Appliances (http://global.gree.com/) is one international household appliance enterprise. Since 2005, Gree has led the production and sales volume of residential air conditioners for 12 consecutive years. Gree has established 11 production bases around the world. In 2015, Gree achieved sales revenue of 110.113 billion RMB, with a net profit of 15.421 billion RMB. Gree ranks No. 385 in Forbes Global 2000, and No. 1 in household appliances industry.

Gree owns remarkable manufacturing strength and technical patents. Only in 2011 has Gree invested more than $¥ 3$ billion in developing products (Gree Electric Appliances: China’s confidence comes from enterprise innovation (In Chinese). Available online: http:/ /scitech.people.com.cn/n/ 2013/1108/c1007-23473421.html (accessed on 20 December 2017)). At present, it has accumulated over 6000 patents at home and abroad, among which there are more than 1300 patents for invention (What's about the Gree electric fan and its price? (In Chinese) Available online: http:/ /zt.pchouse.com.cn/25/ 256406.html (accessed on 20 December 2017)). The Gree 1-Hz Inverter air conditioner, as an industry benchmark, is a successful example of its work on CER, which can cut down on a compressor's starting and stopping frequency as much as possible to reduce the power consumption. This product can keep the compressor operating steadily at a low speed of revolution. A good product is naturally to be favored by consumers.

JD.com is among the most popular B2C online retailers in China. In November 2015, Gree and JD.com signed a framework cooperation agreement to launch deep cooperation in e-commerce, starting their e-supply chain cooperation mode.

Without a price war with other air conditioner brands, Gree and JD.com have made one sales record after another. On 9 January 2017, they worked out an annual sales plan of $¥ 10$ billion. By 18 June, Gree's sales in all of the categories on JD.com were up 656\% year-on-year. By 12 July, Gree's sales totaled $¥ 10$ million in three minutes at its best. Its sales in the first half of the year have exceeded the whole of 2016 (JD.com's 11.11 air conditioning sales reached three times the same period last year and Gree’s sales in seven minutes was more than $¥ 100$ million (In Chinese). Available online: http:/ / www. sohu.com/a/203773496_99905464 (accessed on 20 December 2017)). On 28 October, its single-day sales was up $900 \%$ year-on-year. On 11 November, Gree sold more than $¥ 100$ million products only in seven minutes (China manufacturing climbing again: Gree and JD.com are challenging the $¥ 20$ billion annual target (In Chinese). Available online: http:/ / www.sohu.com/a/219883310_99967243 (accessed on 20 December 2017)). JD.com improved its operation efficiency, and reduced its distribution costs through the application of the internet, which can help manufacturers increase their revenue. However, JD.com 
insists that if the net margin of one product is $10 \%$, it should only take $3 \%$ for itself and let its partner have double revenue.

As can be seen from this case, instead of making much profit from the manufacturer, JD.com not only gave enough benefits to the manufacturers, it also served the consumers with excellent express delivery. Thus, the manufacturer will be motivated enough to improve its CER level and develop more advanced low-carbon products. Without cutting the price, their cooperation provided good products and service to consumers, and thus increased the revenue greatly as well. The benefit of the consumers is their most important concern. Only by satisfying each consumer can the product survive.

\subsection{Numerical Comparison of the Optimal Decision in Two Modes}

In this part, we employ numerical examples to illustrate a comparative analysis of the decisions in different models, which generalize research issues by considering general products, similar to the previous literature [52,53]. Let the parameters in the models be assigned values as $\alpha=1000, \beta=0.5$, $\gamma=0.2, k=10, c=200, t=0.5, f=5000$. Further, consider the following two cases:

(1) Let $\lambda$ be fixed, and $\rho$ be the independent variable, where $1 \leq \rho \leq 0.9$,

(2) Let $\rho$ be fixed, and $\lambda$ be the independent variable, where $1 \leq \lambda \leq 0.9$.

We plot how each decision parameter changes with the corresponding independent variable, as shown in Figures 2-6. Figure 2 is the comparison of the product price in different modes, Figure 3 demonstrates the CER level, Figure 4 describes the service level of the e-commerce platform, and Figure 5 and figure 6 are that of the revenue of the whole supply chain and its member enterprises, respectively.

In the centralized decision mode, the manufacturer and the e-commerce platform work together to optimize the whole supply chain, which hasn't come down to how the revenue will be shared. Hence, all of the decision parameters are independent of $\rho$ in the centralized decision mode. It's applicable to the following. We won't address it anymore.

Figure $2 \mathrm{a}, \mathrm{b}$ shows the comparison of $\lambda=0.2$ and $\lambda=0.6$. We can conclude that the varying ability to respond to consumers' preference for the low-carbon product causes obvious different results between these two decision modes. When $\lambda=0.2$ (see Figure 2a), the ability to respond to consumer preference for the low-carbon product is relatively low. With the rise of the revenue proportion that the e-commerce platform occupies, a high price (higher than the centralized decision mode) seems to be the only choice for the manufacturer to struggle for more revenue. When $\lambda=0.6$ (see Figure 2b), with the increase of the commission fee that the e-commerce platform collects, the product price shows a trend of fall-rise. This trend explains how the manufacturer answers the e-commerce platform's action: the manufacturer has always been trying to make small profits, as well as a quick turnover by reducing the price until $\rho=0.7$, where the price reaches the minimum. Then, the manufacturer switched to the opposite way of pricing, since the low price strategy has no effect. This is the manufacturer's reluctant action to gain more revenue. However, in the centralized decision mode, the reduction in the transaction cost along with the excellent service level attract enough consumers for the supply chain to sell products at a much higher price.

Figure 2c,d presents the comparison of $\rho=0.1$ and $\rho=0.5$. With the change of the revenue-sharing between the e-commerce platform and the manufacturer, when the e-commerce platform tends to occupy a greater share of the revenue $(\rho=0.1)$, the manufacturer will use its pricing to raise the price for more revenue, and even give a higher price with a lower service level than the centralized decision mode. If the commission rate $\rho$ rises to 0.5 , when $\lambda$ is small, then the e-supply chain still has a weak ability to respond to the consumer preference for the low-carbon product, and the decentralized decision mode could offer a price higher than the centralized decision mode. However, once $\lambda$ is more than 0.37 , the centralized decision mode could set a higher price. In any case, when the ability to respond to consumers' preference for the low-carbon product rises, a proper increase in the price just represents what the supply chain has done for developing low-carbon products. 


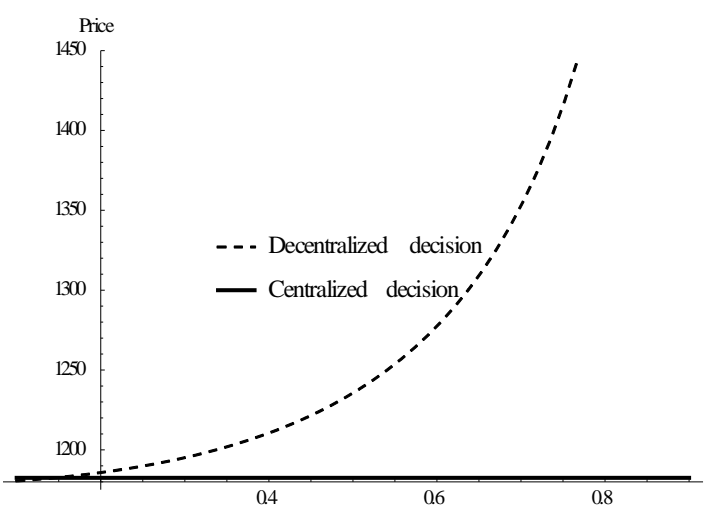

(a) $\lambda=0.2$

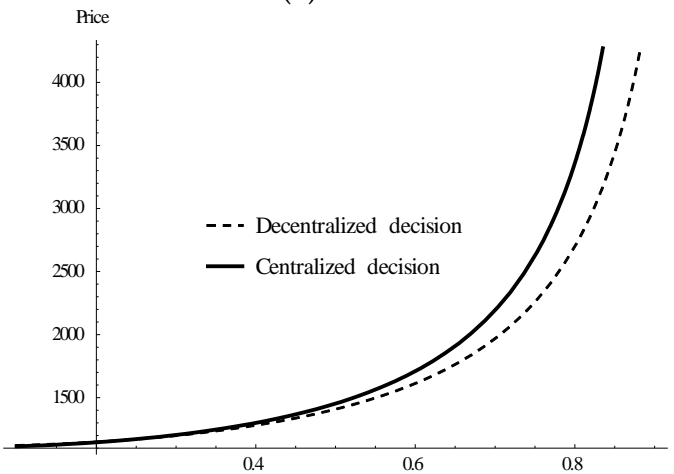

(c) $\rho=0.1$

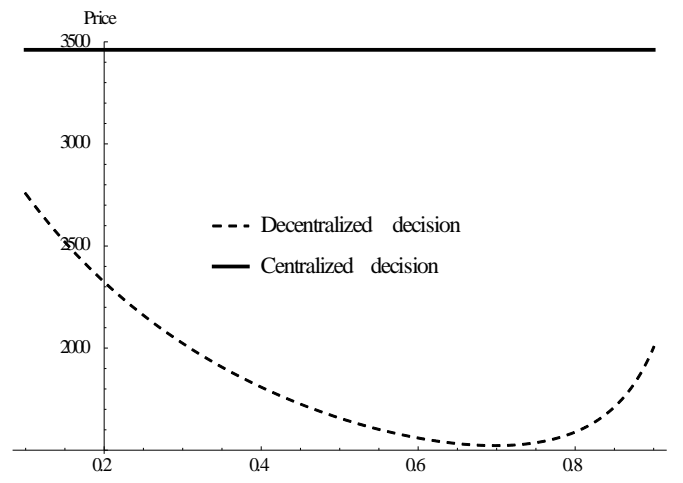

(b) $\lambda=0.6$

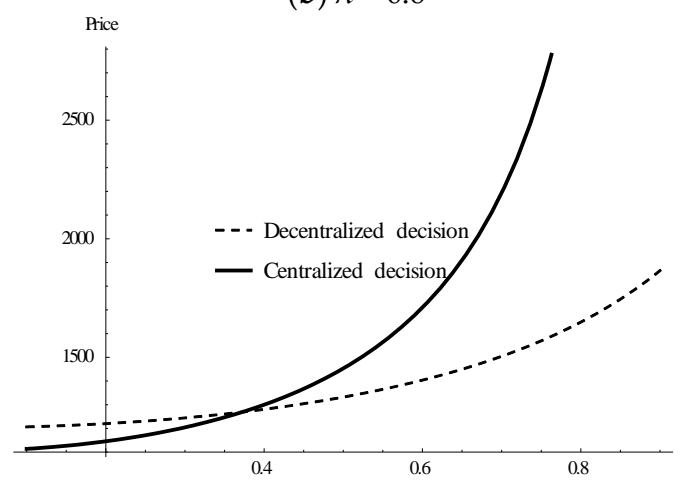

(d) $\rho=0.5$

Figure 2. Comparison of price between two decision modes.

It can be known from Figure 3a that the increase of the e-commerce platform's revenue proportion makes the manufacturer greatly lose the initiative to reduce the carbon emission, and the manufacturer is not willing to do more about that. This is also the proof that the e-commerce platform is the leader in their cooperation. As shown in Figure $2 b$, once $\rho$ is greater than 0.7 , the manufacturer even tries to raise the price in this case, aiming to make much more revenue for itself, which inevitably results in a high price and low low-carbon quality. Then, the revenue of the supply chain is bound to decline clearly. However, Figure $3 b$ demonstrates firmly that no matter what decision mode it adopts, the supply chain should comply with consumers' demand of low-carbon products, and the only difference is that the decentralized decision mode can't guarantee enough revenue for the manufacturer, so that the manufacturer can't be as incentivized to improve the CER level as in the centralized decision mode.

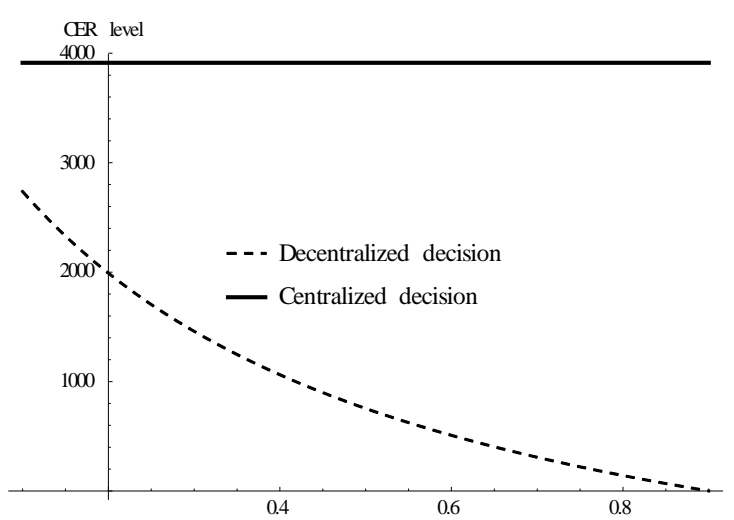

(a) $\lambda=0.6$

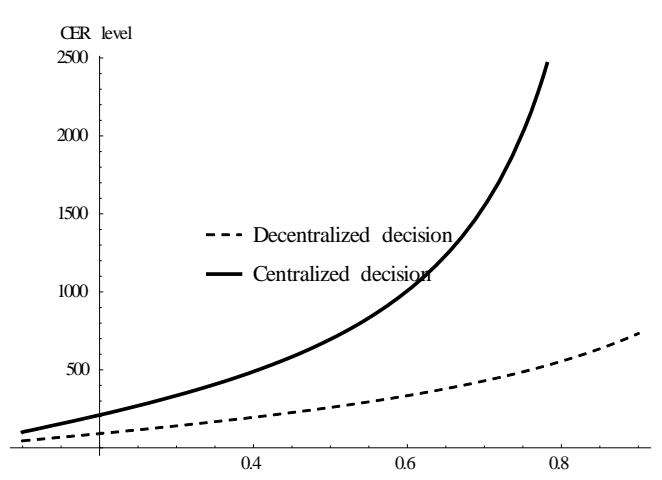

(b) $\rho=0.5$

Figure 3. Comparison of carbon emission reduction (CER) level between the two decision modes. 
We can see from Figure 4a that in the decentralized decision mode, the rise of the revenue proportion encourages the e-commerce platform to keep improving its service level for attracting and maintaining more consumers. However, its service level begins a slow decline once $\rho$ is more than 0.3 . Unfortunately, in the decentralized decision mode, although both the e-commerce platform and the manufacturer separately act in their best interests, their resultant force is negative. The manufacture's measures to raise the price and reduce carbon emission levels without negotiation after its revenue has been squeezed will completely counteract the active efforts of the e-commerce platform to improve the service level and attract more consumers, and in the end force the e-commerce platform to stop offering a better service. This confirms what the centralized decision mode means. Figure $4 \mathrm{~b}$ expresses the case similar to Figure $3 b$.

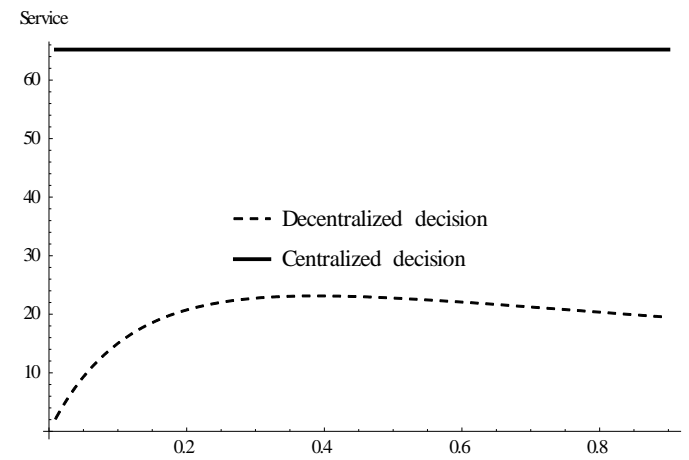

(a) $\lambda=0.6$

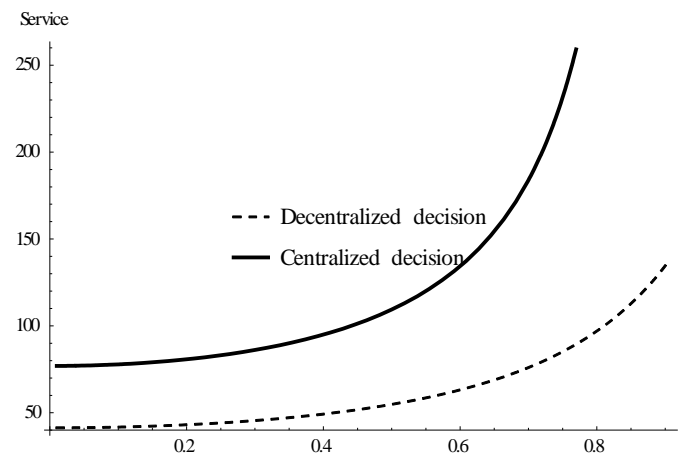

(b) $\rho=0.5$

Figure 4. Comparison of e-commerce platform service level between two decision modes.

It can be derived from Figure 5a,b that the centralized decision mode will help the e-supply chain obtain more revenue than the decentralized one, which has benefited from a higher price (Figure 2), higher CER level (Figure 3), and higher service level (Figure 4) in this mode. However, in the decentralized decision mode, the supply chain's revenue goes down when the commission fee rate that the e-commerce platform collects goes up. It validates the analysis for Figure 2. When the e-commerce platform collects more revenue, the manufacturer also expects to increase its revenue, so it raises the price, as shown in Figure 2. However, this response causes a decline in the sales, and subsequently a fall in the revenue. It appears more remarkable when the ability to respond to consumer preference for the low-carbon product is weak, as can be seen that the curve in Figure 5a has a more obvious downward trend than Figure 5b. So, this is by no means an expected and rational strategy. We can also see from Figure 6a that with the rise of $\rho$, both the revenue of the manufacturer and that of the e-commerce platform show the trend of descending on the whole. Figure 6a also supports Figure 4a. When the e-commerce platform's revenue goes down, it stops providing service with a high level; so, the service level and the revenue are directly related. In the decision mode dominated by the e-commerce platform, the manufacturer will lose more revenue. Figures $5 \mathrm{c}$ and $6 \mathrm{~b}$ indicate that when $\rho$ is fixed, consumers tend to buy low-carbon products, which help both the revenue of the whole e-supply chain and that of the member enterprises, which go up as shown in Figure 2c,d. 


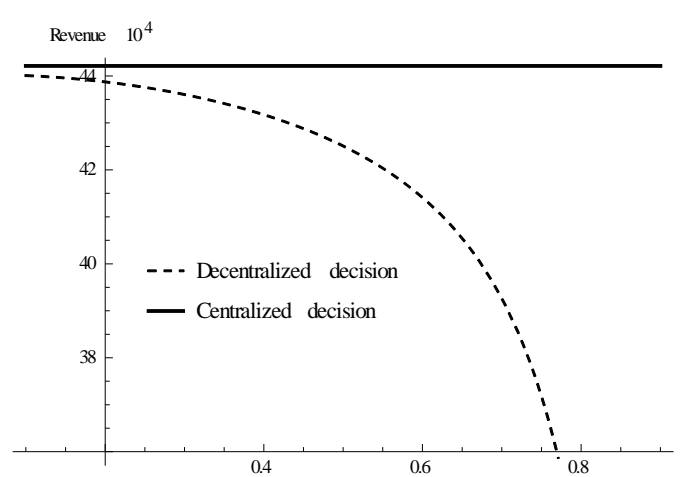

(a) $\lambda=0.2$

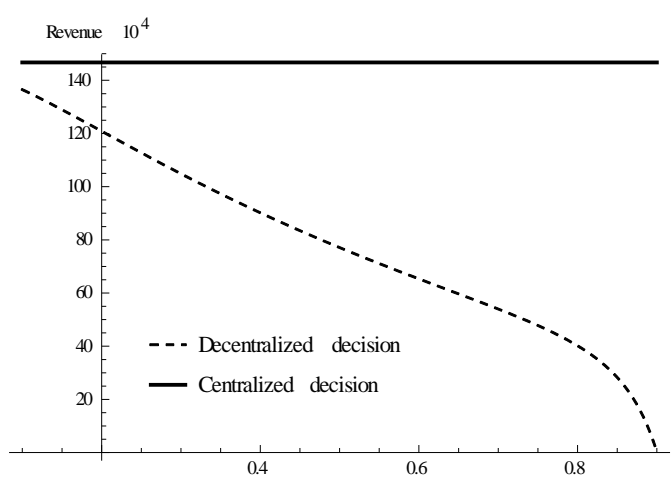

(b) $\lambda=0.6$

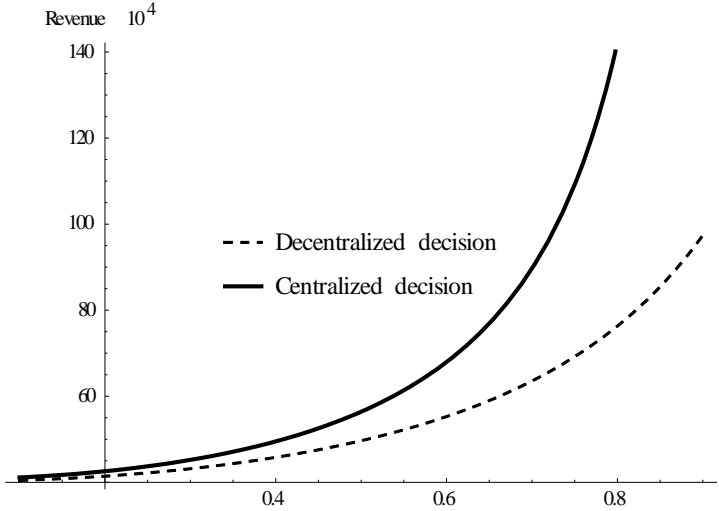

(c) $\rho=0.5$

Figure 5. Comparison of e-supply chain revenue between two decision modes.

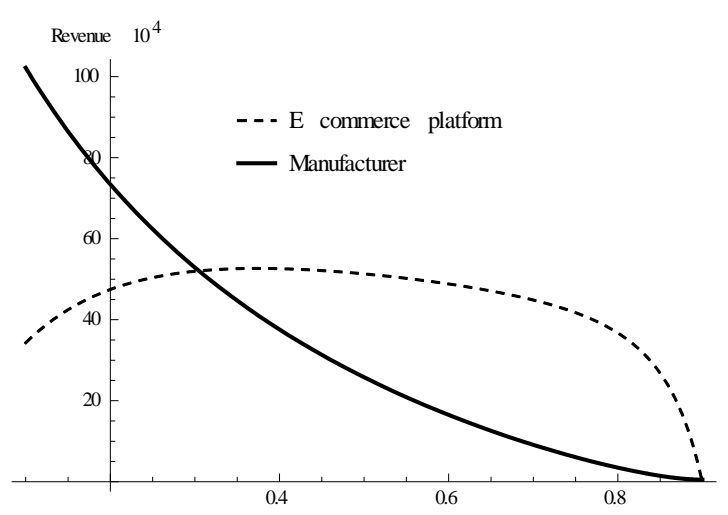

(a) $\lambda=0.6$

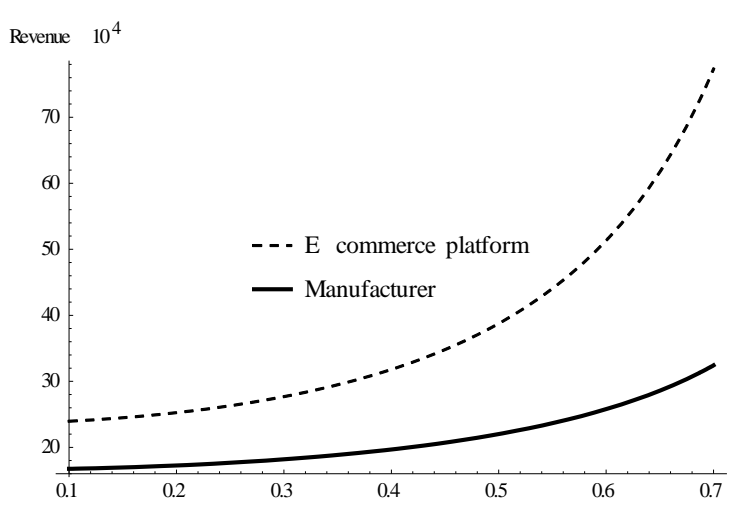

(b) $\rho=0.5$

Figure 6. Revenue comparison between the e-commerce platform and the manufacturer.

\subsection{Coordination}

Let $\alpha=1000, \beta=0.5, \gamma=0.2, \lambda=0.6, k=10, c=200, t=0.5$, and $f=5000$. The optimal decision in the centralized decision mode is as follows:

$\pi_{2}=1.46739 \times 10^{6}, p=3460.87, s=65.22, h=3913.04$.

See Table 3 for the optimal decision corresponding to different $\rho$ in the decentralized decision mode. 
Table 3. The optimal decision results of the decentralized decision mode.

\begin{tabular}{ccccccc}
\hline$\#$ & $\boldsymbol{\rho}$ & $\boldsymbol{p}$ & $\boldsymbol{s}$ & $\boldsymbol{h}$ & $\boldsymbol{\pi}_{\boldsymbol{m}}$ & $\boldsymbol{\pi}_{\boldsymbol{e}}$ \\
\hline 1 & 0.3 & 2023.00 & 22.74 & 1459.32 & $518,950.00$ & $529,591.00$ \\
2 & 0.4 & 1808.61 & 23.13 & 1062.20 & $365,867.00$ & $559,68.00$ \\
3 & 0.5 & 1657.11 & 22.77 & 754.27 & $247,854.00$ & $523,204.00$ \\
4 & 0.6 & 1559.57 & 22.07 & 508.59 & $154,871.00$ & $498,307.00$ \\
5 & 0.7 & 1522.42 & 21.23 & 308.07 & $81,120.80$ & $458,734.00$ \\
6 & 0.8 & 1588.87 & 20.35 & 141.33 & $24,683.10$ & $377,182.00$ \\
\hline
\end{tabular}

Based on CFRCS, the coordinated revenue of the manufacturer and the e-commerce platform are given in Table 4 , in which the range of $\theta$ is determined for a certain $\rho$, and we take two values of $\theta$, which are close to the different ends of the interval, as examples to compute the coordinated revenue.

Table 4. Supply chain coordination results.

\begin{tabular}{cccccc}
\hline$\#$ & $\rho$ & Range of $\boldsymbol{\theta}$ & Certain $\boldsymbol{\boldsymbol { T } _ { \boldsymbol { m } }}$ & $\boldsymbol{\pi}_{\boldsymbol{e}}$ \\
\hline 1 & 0.3 & {$[0.357062,0.642501]$} & 0.40 & 581,957 & 885,435 \\
2 & 0.3 & {$[0.357062,0.642501]$} & 0.60 & 875,435 & 591,957 \\
3 & 0.4 & {$[0.252739,0.643815]$} & 0.30 & 435,217 & $1.03217 \times 10^{6}$ \\
4 & 0.4 & {$[0.252739,0.643815]$} & 0.50 & 802,065 & 665,326 \\
5 & 0.5 & {$[0.172351,0.646853]$} & 0.20 & 288,478 & $1.17891 \times 10^{6}$ \\
6 & 0.5 & {$[0.172351,0.646853]$} & 0.60 & 875,435 & 591,957 \\
7 & 0.6 & {$[0.108949,0.663821]$} & 0.11 & 156,413 & $1.31098 \times 10^{6}$ \\
8 & 0.6 & {$[0.108949,0.663821]$} & 0.65 & 948,804 & 518,587 \\
9 & 0.7 & {$[0.0586897,0.690789]$} & 0.10 & 141,739 & $1.32565 \times 10^{6}$ \\
10 & 0.7 & {$[0.0586897,0.690789]$} & 0.68 & 992,826 & 474,565 \\
11 & 0.8 & {$[0.0202285,0.746365]$} & 0.05 & $68,369.6$ & $1.39902 \times 10^{6}$ \\
12 & 0.8 & {$[0.0202285,0.746365]$} & 0.74 & $1.08087 \times 10^{6}$ & 386,522 \\
\hline
\end{tabular}

It's obvious from Table 4 that with the rise of $\rho$, the e-commerce platform possesses more and more revenue proportion before coordination. Then, there is a larger space for it to share the manufacturer's CER cost during the coordination. So, that's why the range of $\theta$ that will be selected is widening. Both sides have more choices to maximize the supply chain revenue. $\theta$ shows the manufacturer's voice in the supply chain. When $\theta$ is small, the e-commerce platform shares a smaller proportion of the CER cost for the manufacturer; then, the manufacturer also shares a smaller proportion of the revenue. Otherwise, when $\theta$ is large, the e-commerce platform shares much more cost, and the manufacturer shares much more revenue.

\section{Concluding Comments}

In this paper, we addressed the sustainability of the e-supply chain from different perspectives by making the manufacturer as the starting point to reduce carbon emission. Then, we found the relation between the manufacturer's CER behavior and the whole supply chain performance, and designed one exclusive and effective coordination mechanism for the low-carbon e-supply chain system. We also came to the following interesting conclusions.

First, the ability of an e-supply chain to respond to consumers' preference for the low-carbon product has a direct effect on its operation. With the rise of this ability, the e-supply chain could increase the product price, service level, and revenue. Thus, the manufacturer's CER behavior will be a potential source for enterprises to gain more revenue. In particular, it provides those in their mature stage, with a more promising path to higher levels.

Second, in the decentralized decision mode, the e-commerce platform collects only a commission fee, rather than shares the cost of the manufacturer's efforts to reduce the carbon emissions. As a result, if the e-commerce platform possesses a greater proportion of the revenue, the manufacturer, 
for its benefit, tries to raise the price even without improving the low-carbon quality. Then, they are trapped in a vicious circle: poor low-carbon quality and high price $\rightarrow$ lower market share $\rightarrow$ higher revenue proportion possessed by the e-commerce platform $\rightarrow$ lower revenue proportion gained by the manufacturer $\rightarrow$ poorer low-carbon quality and higher price, and this greatly cuts down on the revenue of the manufacturer, the e-commerce platform, and the supply chain.

However, in the centralized decision mode, what the manufacturer and the e-commerce platform will do is maximize the whole supply chain's revenue. They determine the product price, the CER level, and the service level together so that the supply chain can operate in the optimal condition and achieve the optimal revenue. This is in sharp contrast to the decentralized decision mode.

We can learn from the centralized decision mode that the supply chain will obtain the optimal revenue if the manufacturer and the e-commerce platform can reach a certain agreement. The key is to introduce one contract for them to share the profit and the cost, which can be accepted by both sides. That is, if the e-commerce platform possesses more revenue, then it should share more of the CER cost and adjust the fixed technical fee to meet the manufacturer's demand for deserved revenue. This directs one benign and sustainable development path for the manufacturer, the e-commerce platform, and the supply chain.

This paper tries to analyze the decisions and coordination required in a low-carbon e-supply chain considering manufacturer's CER behavior. However, in practice, other factors, e.g., consumers' preferences for low-carbon products, the technical difficulty of CER, and product lifecycle, etc., will also have an effect on the supply chain decision to some extent. Then, the manufacturer mustn't be the only party that can reduce the carbon emission, so its CER behavior should also be combined with other members in the e-supply chain. Research about them will be further addressed in future study.

Author Contributions: Q.H. and Y.W. conceived the framework of this paper; Q.H. computed the models, collected the data and examples, analyzed the data and wrote the paper; Y.W. designed the coordination mechanism.

Acknowledgments: This work is financially supported by the National Natural Science Foundation of China (71501111) and Natural Science Foundation of Shandong Province (ZR2014JL046).

Conflicts of Interest: The authors declare no conflict of interest. The founding sponsors had no role in the design of the study; in the collection, analyses, or interpretation of data; in the writing of the manuscript, and in the decision to publish the results.

\section{Appendix A. Proof of Proposition 1}

$$
\begin{gathered}
\frac{\partial p_{1}^{*}}{\partial \lambda}=\frac{2 k t \lambda\left\{k[\alpha(1-\rho)-c \beta]\left[2 t \beta+\lambda^{2}(-1+\rho)\right]^{2}+2 t \beta \gamma^{2} \rho\left[(1-\rho)\left(t \alpha-c \lambda^{2}\right)+c t \beta\right]\right\}}{\left\{k\left[2 t \beta+\lambda^{2}(\rho-1)\right]^{2}-2 t^{2} \beta \gamma^{2} \rho\right\}^{2}} \\
\frac{\partial p_{2}^{*}}{\partial \lambda}=\frac{2 k^{2} t(\alpha-c \beta) \lambda}{\left[2 k t \beta-\left(t \gamma^{2}+k \lambda^{2}\right)\right]^{2}}
\end{gathered}
$$

Since $\alpha$ is a large enough number, $(1-\rho) \alpha>c \beta$ and $\alpha>c \beta$.

Thus, $\frac{\partial p_{1}^{*}}{\partial \lambda} \geq 0, \frac{\partial p_{2}^{*}}{\partial \lambda} \geq 0$; that is, $p_{1}^{*}$ and $p_{2}^{*}$ are direct proportional to $\lambda$, respectively. $\square$

\section{Appendix B. Proof of Proposition 2}

$$
\begin{aligned}
& h_{2}^{*}=\frac{(\alpha-c \beta) k \lambda}{h_{1}^{*}}=\frac{k A^{2}-2 t^{2} \beta \gamma^{2} \rho}{2 k t \beta-\left(t \gamma^{2}+k \lambda^{2}\right)} \times \frac{\left(\alpha A B+c t \beta \gamma^{2} \rho\right)}{\lambda(k A) k \lambda} \times \frac{k A^{2}-2 t^{2} \beta \gamma^{2} \rho}{2 k t \beta-\left(t \gamma^{2}+k \lambda^{2}\right)} \\
& \quad=\frac{\left(\alpha-c \beta+c t \beta \gamma^{2} \rho\right)}{\lambda(k A B+1)}
\end{aligned}
$$

By comparison of the coefficients of $\alpha$, we can know $\frac{h_{2}^{*}}{h_{1}^{*}} \geq 1$. Then, $h_{1}^{*} \leq h_{2}^{*}$. 
In similar way, since $\alpha$ is a large enough number, by comparison of the coefficients of $\alpha$ in $\frac{\partial h_{1}^{*}}{\partial \lambda}$, we can get $\frac{\partial h_{1}^{*}}{\partial \lambda} \geq 0 . h_{1}^{*}$ is direct proportional to $\lambda$ :

$$
\frac{\partial h_{2}^{*}}{\partial \lambda}=\frac{k(\alpha-c \beta)\left[2 k t \beta-\left(t \gamma^{2}+k \lambda^{2}\right)\right]}{\left[2 k t \beta-\left(t \gamma^{2}+k \lambda^{2}\right)\right]^{2}}
$$

Since $\alpha>c \beta$ and $t \gamma^{2}+k \lambda^{2}<2 k t \beta, \frac{\partial h_{2}^{*}}{\partial \lambda} \geq 0$. So, $h_{2}^{*}$ is direct proportional to $\lambda$.

$$
\frac{\partial h_{1}^{*}}{\partial \rho}=\frac{k \beta \lambda\left(-2 t \alpha+c \lambda^{2}\right)\left[k A^{2}+t \gamma^{2}\left(2 t \beta-\lambda^{2}\left(\rho^{2}-1\right)\right)\right]}{D^{2}}
$$

We can know $\frac{\partial h_{1}^{*}}{\partial \rho} \leq 0$ from the coefficient of $\alpha$. Then, $h_{1}^{*}$ is reverse proportional to $\rho . \square$

\section{Appendix C. Proof of Proposition 3}

$$
\begin{aligned}
& \frac{s_{2}^{*}}{s_{1}^{*}}=\frac{(\alpha-c \beta) t \gamma}{2 k t \beta-\left(t \gamma^{2}+k \lambda^{2}\right)} \times \frac{k A^{2}-2 t^{2} \beta \gamma^{2} \rho}{t \beta \gamma \rho\left(2 t \alpha-c \lambda^{2}\right)} \\
& \quad=\frac{(\alpha-c \beta) t \gamma}{t \beta \gamma \rho\left(2 t \alpha-c \lambda^{2}\right)} \times \frac{k A^{2}-2 t^{2} \beta \gamma^{2} \rho}{2 k t \beta-\left(t \gamma^{2}+k \lambda^{2}\right)}
\end{aligned}
$$

By comparison of the coefficients of $\alpha$, we can know $\frac{s_{2}^{*}}{s_{1}^{*}} \geq 1$. Then, $s_{1}^{*} \leq s_{2}^{*}$.

$$
\begin{gathered}
\frac{\partial s_{1}^{*}}{\partial \lambda}=\frac{2 t \beta \gamma \lambda \rho\left\{k A\left[2 t(2 \alpha(1-\rho)-c \beta)-c \lambda^{2}(1-\rho)\right]+2 c t^{2} \beta \gamma^{2} \rho\right\}}{D^{2}} \\
\frac{\partial s_{2}^{*}}{\partial \lambda}=\frac{2 k t(\alpha-c \beta) \gamma \lambda}{\left[2 k t \beta-\left(t \gamma^{2}+k \lambda^{2}\right)\right]^{2}}
\end{gathered}
$$

Since $\alpha$ is a large enough number, numerators of both $\frac{\partial s_{1}^{*}}{\partial \lambda}$ and $\frac{\partial s_{2}^{*}}{\partial \lambda}$ are no less than 0 .

Thus, $s_{1}^{*}$ and $s_{2}^{*}$ are directly proportional to $\lambda$, respectively.

\section{Appendix D. Proof of Proposition 4}

By checking each coefficient of $\alpha$ in $\pi_{2}^{*}-\pi_{1}^{*}$, we can find they are all no less than 0 .

So, $\pi_{1}^{*} \leq \pi_{2}^{*}$.

$$
\begin{gathered}
\pi_{1}^{*}=\frac{t}{2 D^{2}}\left[k t^{2} \beta^{2} \gamma^{2}\left(2 t \alpha-c \lambda^{2}\right)^{2} \rho^{2}-\lambda^{2} C^{2}+\frac{2 c \beta C D}{1-\rho}+\frac{2 \beta(1+\rho) C\left[c t^{2} \beta \gamma^{2} \rho+k A(t B-c A)\right]}{(1-\rho)^{2}}\right] \\
D=k A^{2}-2 t^{2} \beta \gamma^{2} \rho \\
=k\left[2 t \beta+\lambda^{2}(\rho-1)\right]-2 t^{2} \beta \gamma^{2} \rho \\
\frac{\partial D}{\partial \rho}=-2 t^{2} \beta \gamma^{2}+2 k \lambda^{2}\left[2 t \beta+\lambda^{2}(\rho-1)\right] .
\end{gathered}
$$

$\frac{\partial D}{\partial \rho}$ is an increasing function of $\rho$. Therefore, $\frac{t}{2 D^{2}}$ is an decreasing function of $\rho$.

Similarly, all of the items in the bracket of $\pi_{1}^{*}$ are increasing with $\rho$. So, $\pi_{1}^{*}$ is reversely proportional to $\rho$.

$$
\begin{gathered}
\pi_{1}=-k s^{2} / 2-h^{2} t / 2+(p-c)(\alpha-p \beta+s \gamma)+h(p-c) \lambda \\
\frac{\partial \pi_{1}}{\partial \lambda}=h(p-c) \\
\frac{\partial \pi_{2}^{*}}{\partial \lambda}=\frac{k^{2} t(\alpha-c \beta)^{2} \lambda}{\left[2 k t \beta-\left(t \gamma^{2}+k \lambda^{2}\right)\right]^{2}}
\end{gathered}
$$


It's clear that $\frac{\partial \pi_{1}}{\partial \lambda} \geq 0$ and $\frac{\partial \pi_{2}^{*}}{\partial \lambda} \geq 0$. So, $\pi_{1}^{*}$ and $\pi_{2}^{*}$ are directly proportional to $\lambda$, respectively.

\section{Appendix E. Proof of Propositions 5 and 6}

Let:

$$
\begin{gathered}
\operatorname{Bound}_{l}(\lambda, \gamma, \beta) \triangleq \frac{2\left(f+\pi_{m}^{*}\right)\left(2 k t \beta-t \gamma^{2}-k \lambda^{2}\right)}{k t(\alpha-c \beta)^{2}} \\
\operatorname{Bound}_{u}(\lambda, \gamma, \beta) \triangleq \frac{k t(\alpha-c \beta)^{2}-2\left(\pi_{e}^{*}-f\right)\left(2 k t \beta-t \gamma^{2}-k \lambda^{2}\right)}{k t(\alpha-c \beta)^{2}}
\end{gathered}
$$

Then:

$$
\begin{gathered}
\frac{\partial \text { Bound }_{l}(\lambda, \gamma, \beta)}{\partial \lambda}=-\frac{4\left(\pi_{m}^{*}+f\right) \lambda}{t(\alpha-c \beta)^{2}}, \frac{\partial \text { Bound }_{u}(\lambda, \gamma, \beta)}{\partial \lambda}=\frac{4\left(\pi_{e}^{*}-f\right) \lambda}{t(\alpha-c \beta)^{2}} \\
\frac{\partial \text { Bound }_{l}(\lambda, \gamma, \beta)}{\partial \gamma}=-\frac{4\left(\pi_{m}^{*}+f\right) \gamma}{t(\alpha-c \beta)^{2}}, \frac{\partial \text { Bound }_{u}(\lambda, \gamma, \beta)}{\partial \gamma}=\frac{4\left(\pi_{e}^{*}-f\right) \gamma}{t(\alpha-c \beta)^{2}} \\
\frac{\partial \text { Bound }_{l}(\lambda, \gamma, \beta)}{\partial \beta}=\frac{4\left(\pi_{m}^{*}+f\right)\left[k t(\alpha+c \beta)-c\left(t \gamma^{2}+k \lambda^{2}\right)\right]}{k t(\alpha-c \beta)^{2}} \\
\frac{\text { Bound }_{u}(\lambda, \gamma, \beta)}{\partial \beta}=-\frac{4\left(\pi_{e}^{*}-f\right)\left[k t(\alpha+c \beta)-c\left(t \gamma^{2}+k \lambda^{2}\right)\right]}{k t(\alpha-c \beta)^{2}}
\end{gathered}
$$

Similar to the previous proof, we can compare and conclude that:

$$
\begin{aligned}
& \frac{\text { BBound }_{l}(\lambda, \gamma, \beta)}{\partial \lambda} \leq 0, \frac{\partial \text { Bound }_{l}(\lambda, \gamma, \beta)}{\partial \gamma} \leq 0, \frac{\partial \text { Bound }_{u}(\lambda, \gamma, \beta)}{\partial \lambda} \geq 0 \\
& \frac{\partial \text { Bound }_{u}(\lambda, \gamma, \beta)}{\partial \gamma} \geq 0, \frac{\partial \text { Bound }_{l}(\lambda, \gamma, \beta)}{\partial \beta} \geq 0, \frac{\partial \text { Bound }_{u}(\lambda, \gamma, \beta)}{\partial \beta} \leq 0 .
\end{aligned}
$$

So, the lower bound of the manufacturer's bargaining power in the CFRCS mechanism, $\theta$, is reversely proportional to the elasticity coefficient of CER, $\lambda$, and the elasticity coefficient of the service level, $\gamma$, while its upper bound is directly proportional to them, respectively. What's more, the lower bound of the manufacturer's bargaining power in the CFRCS mechanism, $\theta$, is directly proportional to the elasticity coefficient of price, $\beta$, while its upper bound is reversely proportional to it. $\square$

\section{References}

1. Benjaafar, S.; Li, Y.; Daskin, M. Carbon footprint and the management of supply chain: Insights from simple models. IEEE Trans. Autom. Sci. Eng. 2013, 10, 99-116. [CrossRef]

2. The Guardian. Available online: https://www.theguardian.com/environment/2011/jul/01/carbon-trustresearch-footprint-consumer-demand (accessed on 1 January 2018).

3. Vanclay, J.K.; Shortiss, J.; Aulsebrook, S.; Gillespie, A.M.; Howell, B.C.; Johanni, R.; Maher, M.J.; Mitchell, K.M.; Stewart, M.D.; Yates, J. Customer response to carbon labelling of groceries. J. Consum. Policy 2011, 34, 153-160. [CrossRef]

4. Food Marketing Institute. Available online: https://www.fmi.org/docs/sustainability/BBMG_Conscious_ Consumer_White_Paper.pdf (accessed on 3 January 2018).

5. Plambeck, E.L. Reducing greenhouse gas emissions through operations and supply chain management. Energy Econ. 2012, 34, S64-S74. [CrossRef]

6. Turki, S.; Rezg, N. Unreliable manufacturing supply chain optimisation based on an infinitesimal perturbation analysis. Int. J. Syst. Sci. Oper. Logist. 2016, 5, 25-44. [CrossRef]

7. Turki, S.; Didukh, S.; Sauvey, C.; Rezg, N. Optimization and analysis of a manufacturing-remanufacturing-transport-warehousing system within a closed-loop supply chain. Sustainability 2017, 9, 561. [CrossRef] 
8. Mota, B.; Gomes, M.I.; Ana, C.; Barbosa-Povoa, A.P. Towards supply chain sustainability: Economic, environmental and social design and planning. J. Clean. Prod. 2015, 105, 14-27. [CrossRef]

9. Xu, L.; Wang, C.; Li, H. Decision and coordination of low-carbon supply chain considering technological spillover and environmental awareness. Sci. Rep. 2017, 7, 3107. [CrossRef] [PubMed]

10. Zheng, Y.; Liao, H.; Yang, X. Stochastic pricing and order model with transportation mode selection for low-carbon retailers. Sustainability 2016, 8, 48. [CrossRef]

11. Freis, J.; Vohlidka, P.; Günthner, W.A. Low-carbon warehousing: Examining impacts of building and intra-logistics design options on energy demand and the $\mathrm{CO}_{2}$ emissions of logistics centers. Sustainability 2016, 8, 448. [CrossRef]

12. Du, S.; Hu, L.; Wang, L. Low-carbon supply policies and supply chain performance with carbon concerned demand. Ann. Oper. Res. 2017, 255, 569-590. [CrossRef]

13. Du, S.; Zhu, J.; Jiao, H.; Ye, W. Game-theoretical analysis for supply chain with consumer preference to low carbon. Int. J. Prod. Res. 2015, 53, 3753-3768. [CrossRef]

14. Brandenburg, M. Low carbon supply chain configuration for a new product-A goal programming approach. Int. J. Prod. Res. 2015, 53, 6588-6610. [CrossRef]

15. Dadhich, P.; Genovese, A.; Kumar, N.; Acquaye, A. Developing sustainable supply chains in the UK construction industry: A case study. Int. J. Prod. Econ. 2014, 164, 271-284. [CrossRef]

16. Su, J.; Li, C.; Tsai, S.B.; Lu, H.; Liu, A.; Chen, Q. A sustainable closed-loop supply chain decision mechanism in the electronic sector. Sustainability 2018, 10, 1295. [CrossRef]

17. Shaw, K.; Shankar, R.; Yadav, S.S.; Thakur, L.S. Modeling a low-carbon garment supply chain. Prod. Plan. Control 2013, 24, 851-865. [CrossRef]

18. Poirier, C.C.; Bauer, M.J. E-supply chain: Using the internet to revolutionize your business. Int. J. Qual. Reliab. Manag. 2002, 19, 485-486. [CrossRef]

19. He, R.; Xiong, Y.; Lin, Z. Carbon emissions in a dual channel closed loop supply chain: The impact of consumer free riding behavior. J. Clean. Prod. 2016, 134, 384-394. [CrossRef]

20. Guo, J.; Wang, X.; Fan, S.; Gen, M. Forward and reverse logistics network and route planning under the environment of low-carbon emissions: A case study of Shanghai fresh food E-commerce enterprises. Comput. Ind. Eng. 2017, 106, 351-360. [CrossRef]

21. Valverde, R.; Saadé, R.G. The effect of E-supply chain management systems in the North American electronic manufacturing services industry. J. Theor. Appl. Electron. Commer. Res. 2015, 10, 79-98. [CrossRef]

22. Cagliano, A.C.; Marco, A.D.; Rafele, C. E-grocery supply chain management enabled by mobile tools. Bus. Process Manag. J. 2017, 23, 47-70. [CrossRef]

23. Kiselicki, M.; Josimovski, S.; Joncheski, L. Implementation of internet technologies in the supply chain of SEMs in Macedonia. J. Sustain. Dev. 2015, 5, 69-87.

24. Piera, C.; Roberto, C.; Giuseppe, C.; Teresa, M. E-procurement and E-supply Chain: Features and Development of E-collaboration. IERI Procedia 2014, 6, 8-14. [CrossRef]

25. Yi, Y.; Li, J. Cost-sharing contracts for energy saving and emissions reduction of a supply chain under the conditions of government subsidies and a carbon tax. Sustainability 2018, 10, 895. [CrossRef]

26. Li, X.; Wang, Q. Coordination mechanisms of supply chain systems. Eur. J. Oper. Res. 2007, 179, 1-16. [CrossRef]

27. Hou, Y.; Wei, F.; Li, S.; Huang, Z.; Ashley, A. Coordination and performance analysis for a three-echelon supply chain with a revenue sharing contract. Int. J. Prod. Res. 2017, 55, 202-227. [CrossRef]

28. Palsule-Desai, O.D. Supply chain coordination using revenue-dependent revenue sharing contracts. Omega 2013, 41, 780-796. [CrossRef]

29. Cachon, G.P.; Lariviere, M.A. Supply Chain Coordination with Revenue-Sharing Contracts: Strengths and Limitations. Manag. Sci. 2005, 51, 30-44. [CrossRef]

30. Giannoccaro, I.; Pontrandolfo, P. Supply chain coordination by revenue sharing contracts. Int. J. Prod. Econ. 2004, 89, 131-139. [CrossRef]

31. Wei, Y.; Choi, T.M. Mean-variance analysis of supply chains under wholesale pricing and profit sharing schemes. Eur. J. Oper. Res. 2010, 204, 255-262. [CrossRef]

32. Hou, J.; Zeng, A.; Zhao, L. Coordination with a backup supplier through buy-back contract under supply disruption. Transp. Res. Part E Logist. Transp. Rev. 2010, 46, 881-895. [CrossRef] 
33. Xiong, H.; Chen, B.; Xie, J. A composite contract based on buy back and quantity flexibility contracts. Eur. J. Oper. Res. 2011, 210, 559-567. [CrossRef]

34. Wang, F.; Zhuo, X.; Niu, B. Sustainability analysis and buy-back coordination in a fashion supply chain with price competition and demand uncertainty. Sustainability 2017, 9, 25. [CrossRef]

35. Zhang, Q.; Dong, M.; Luo, J.; Segerstedt, A. Supply chain coordination with trade credit and quantity discount incorporating default risk. Int. J. Prod. Econ. 2014, 153, 352-360. [CrossRef]

36. Zissis, D.; Ioannou, G.; Burnetas, A. Supply chain coordination under discrete information asymmetries and quantity discounts. Omega 2015, 53, 21-29. [CrossRef]

37. Sarkar, B. Supply chain coordination with variable backorder, inspections, and discount policy for fixed lifetime products. Math. Probl. Eng. 2016, 2016, 6318737. [CrossRef]

38. Chiu, C.H.; Choi, T.M.; Tang, C.S. Price, rebate, and returns supply contracts for coordinating supply chains with price-dependent demands. Prod. Oper. Manag. 2011, 20, 81-91. [CrossRef]

39. Zhang, J.; Gou, Q.; Liang, L.; Huang, Z. Supply chain coordination through cooperative advertising with reference price effect. Omega 2013, 41, 345-353. [CrossRef]

40. Taylor, T.A. Supply chain coordination under channel rebates with sales effort effects. Manag. Sci. 2002, 48, 992-1007. [CrossRef]

41. Kim, J.S.; Park, S., II; Shin, K.Y. A quantity flexibility contract model for a system with heterogeneous suppliers. Comput. Oper. Res. 2014, 41, 98-108. [CrossRef]

42. Li, X.; Lian, Z.; Choong, K.K.; Liu, X. A quantity-flexibility contract with coordination. Int. J. Prod. Econ. 2016, 179, 273-284. [CrossRef]

43. Jaber, M.Y.; Glock, C.H.; El Saadany, A.M.A. Supply chain coordination with emissions reduction incentives. Int. J. Prod. Res. 2013, 51, 69-82. [CrossRef]

44. Bi, R. E-supply chain coordination and SME performance: An empirical investigation. Electron. J. Inf. Syst. Eval. 2017, 20, 76-84.

45. Wu, C. Price and service competition between new and remanufactured products in a two echelon supply chain. Int. J. Prod. Econ. 2012, 140, 496-507. [CrossRef]

46. Nair, A.; Narasimhan, R. Dynamics of competing with quality-and advertising-based goodwill. Eur. J. Oper. Res. 2006, 175, 462-474. [CrossRef]

47. Yao, D.; Liu, J. Competitive pricing of mixed retail and e-tail distribution channels. Omega 2005, 33, $235-247$. [CrossRef]

48. Yu, Y.; Wang, X.; Zhong, R.; Huang, G.Q. E-commerce logistics in supply chain management: Practice Perspective. Procedia CIRP 2016, 52, 179-185. [CrossRef]

49. Turocy, T.L.; Stengel, B. Von. Game Theory. Encycl. Inf. Syst. 2003, 2, 403-420. [CrossRef]

50. Feng, L.; Govindan, K.; Li, C. Strategic planning: Design and coordination for dual-recycling channel reverse supply chain considering consumer behavior. Eur. J. Oper. Res. 2017, 260, 601-612. [CrossRef]

51. Nie, T.; Du, S. Dual-fairness supply chain with quantity discount contracts. Eur. J. Oper. Res. 2017, 258, 491-500. [CrossRef]

52. Qin, F.; Mai, F.; Fry, M.J.; Raturi, A.S. Supply-chain performance anomalies: Fairness concerns under private cost information. Eur. J. Oper. Res. 2016, 252, 170-182. [CrossRef]

53. Pu, X.; Gong, L.; Han, X. Consumer free riding: Coordinating sales effort in a dual-channel supply chain. Electron. Commer. Res. Appl. 2017, 22, 1-12. [CrossRef]

(C) 2018 by the authors. Licensee MDPI, Basel, Switzerland. This article is an open access article distributed under the terms and conditions of the Creative Commons Attribution (CC BY) license (http://creativecommons.org/licenses/by/4.0/). 